COMPUTATIONAL METHODS IN SCIENCE AND TECHNOLOGY 7 (2), 65-74 (2001)

\title{
CHOSEN ASPECTS OF MODERN CAPP SYSTEMS
}

\author{
IVAN KURIC ${ }^{1}$ AND STANISLAW LEGUTKO ${ }^{2}$ \\ ${ }^{1}$ Faculty of Mechanical Engineering, Department of Measurement and Automation, \\ University of Zilina, SK-010 01 Zilina, Slovak Republic \\ ${ }^{2}$ Poznań University of Technology, Institute of Mechanical Technology, \\ Piotrowo 3, 61-138 Poznań, Poland \\ (Received 12 December, 2000)
}

\begin{abstract}
Process planning is a task that requires a significant amount of both time and experience. Computer support or computerized process planning systems can help to reduce a process planning time and increase plan consistency and efficiency. There are two approaches for creation and processing of process plan based on computer support and advanced planning methods: variant method based on Group Technology and generative method. Authors present new approach to this problem that consists of parameterisation of process plan and association with part features. Several important aspects of methodology for generative CAPP system have been described. The frame of new conception of design CAD/CAPP system has been also presented.
\end{abstract}

\section{INTRODUCTION}

The engineering drawing and the process planning such as the main engineering activities are critical production cost factors. The process planning also very effects other important factor response time to market. Accordingly, consistent computer aid can reduce response time to market and also production cost. These factors impact on competitive advantage as a very important tool of market success.

The Computer Aided Process Planning (CAPP) represents the implemented methodology of process planning in the software package. The CAPP system has to solve the planning activities such as selection of machining operations, sequencing of machining operations, selection of cutting tools, determining setup requirements, calculations of cutting parameters, tool path planning, generation of NC part programs, design ofjigs and fixtures, etc. Process planning is one of labour activities in a preparatory stage of manufacturing. Process planning is a result of engineering planning activities of process planners which prepare a list of processes needed to convert a raw material shape as a starting point into a predetermined final shape.

\section{SYSTEM VIEW ON CAPP}

Process planning is a task that requires a significant amount of both time and experience. Computer support or computerized process planning systems can help reduce a process planning time and increase plan consistency and efficiency. Developments in computer based planning are attempts to free the human from the planning process and to eliminate decisions required during design and planning. The advantage of automated manufacturing process planning is undisputed. There are two approaches for creation and processing of process plan based on computer support and advanced planning methods. The first approach is based on Group Technology utilizing 
the variant method or the variant process planning), the second approach is the exact mathematical principle based on modelling of part, manufacturing knowledge and process plan (generative method or generative process planning). The two approaches are generally different. CAPP systems have various levels of human intervention according to the approaches used.

In the first approach - Group Technology based approach - a planner retrieves the plan for similar components using coding and classifications of parts. The planner edits the retrieved plan to create a variant to suit the specific requirements of the component being planned. This method is based on the principle that parts with similar properties (geometrical, material, qualitative, technological, etc.) have similar process plans (Fig. 1). The computer aid is used to assist in identifying similar plans, retrieving them and editing the plans according to the geometrical dif-ference. In variant CAPP system the process plan is assigned for the whole part according to the global part information. Parametric information between the technological operations and the part feature does not exist.

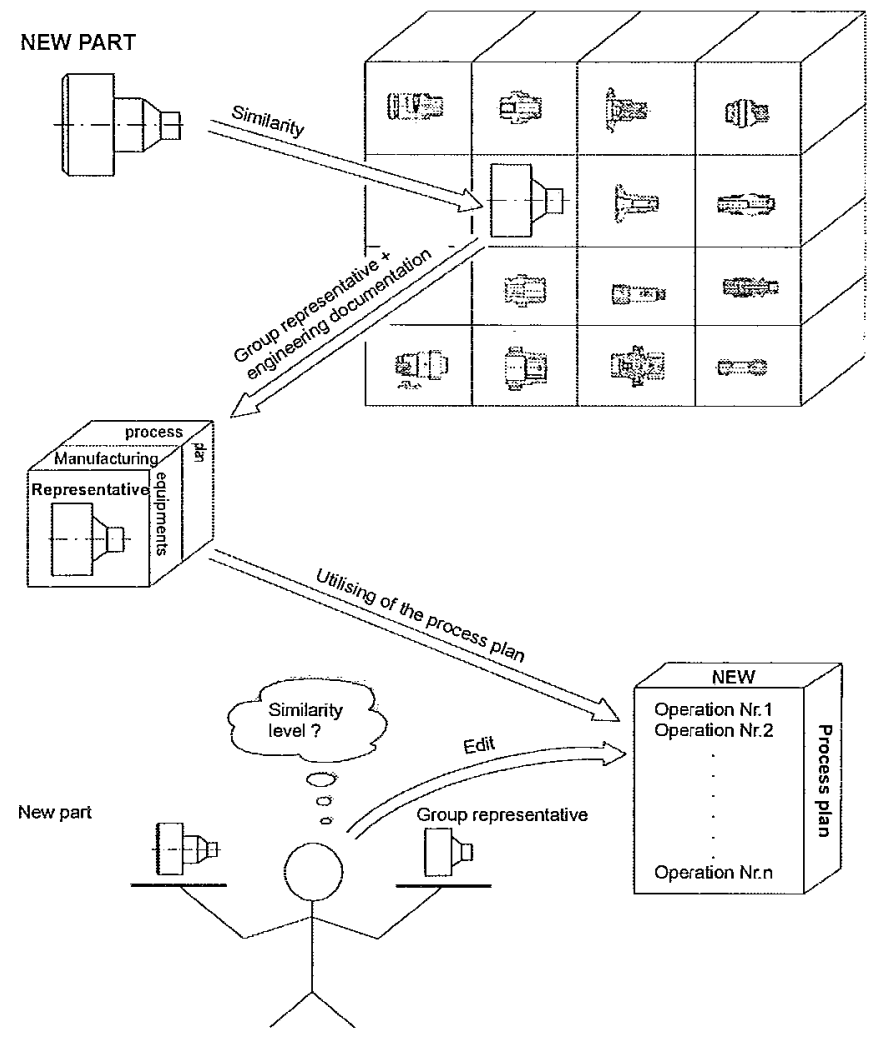

Fig. 1. Principle of CAPP system based on Group Technology

In the second approach - generative method - the process plan for a new part is automatically synthesized. The generative CAPP system, also called exact system, creates the process plan from information available in manufacturing databases according to a CAPP methodology. The generative CAPP system operates without or with little human intervention. The creation of the pro- 
cess plan goes out from the part features. Each of the part features can be manufacturable by several technological operations (Fig. 2). For individual feature from manufacturing knowledge base, the process operations (technological transformer) are generated. From a set of convenient technological transformers an optimal aggregate of technological transformers is extracted. There is parametric information between the technological operation and the part feature.

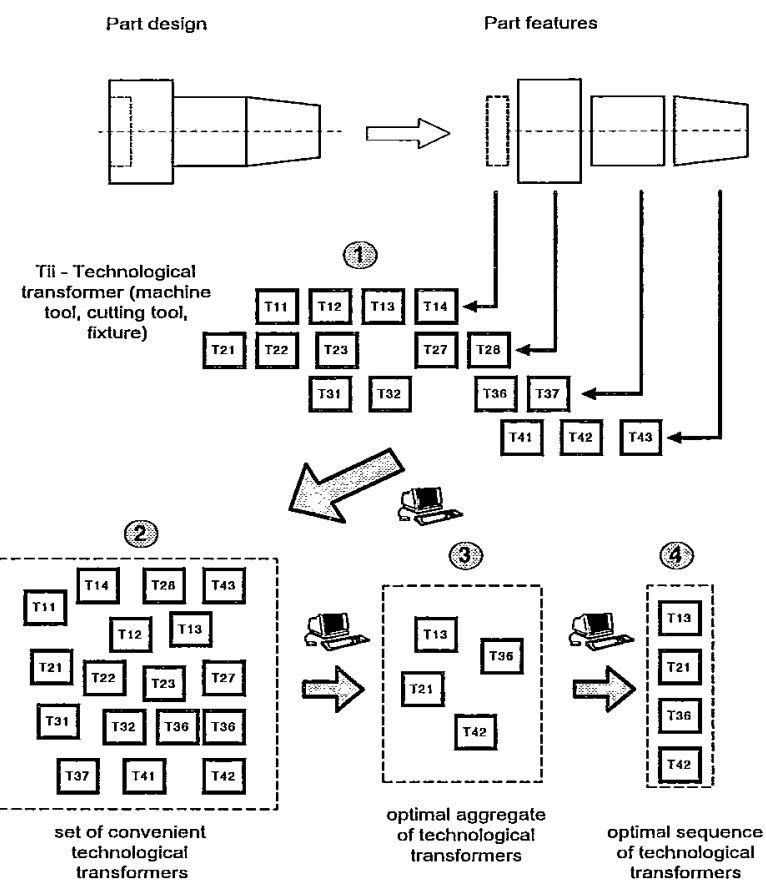

Fig. 2. Principle of the generative CAPP approach

The manufacturing knowledge is one of the basic information bases for automated process planning. The manufacturing knowledge in the variant CAPP systems is placed in standard plans for each family group. Knowledge is complexly expressed in manufacturing, fixturing and heat treatment instructions. The knowledge is represented in textual or coded form and is not systematically divided into knowledge bases. The knowledge in the generative CAPP systems is placed in the individual bases. They should consist of information on manufacturing methods, manufacturing equipment, fixturing, heat treatment, product feature structure, etc. The individual bases are mutual in relation to. The knowledge is directly expressed and is represented in various representation schemes (production rules, frames, decision trees, decision tables, semantic nets). The two basic approaches require the different describing of the part properties. The generative CAPP system needs the unambiguous description of the geometrical, topological and technological part properties. For variant CAPP approach it is convenient to have ambiguous part information, for example some of well-know GT codes (Opitz, CODE, Miclass, Dclass code). The basic difference for the individual process planning task is shown on Table I. 
Table I. Individual activities for two different methods in CAPP systems

\begin{tabular}{ccc}
\hline Activity - task - parameter & Variant CAPP & Generative CAPP \\
\hline Description of part & Unambiguous & Ambiguous \\
Expression of manufacturing knowledge & Implicit & Explicit \\
Location of manufacturing knowledge & Process plans & Individual databases \\
Integration with CAD & Partial & Complete \\
Elaboration of CAD data & Partial & Complete \\
Type of process plan & Textual, pictographic & NC code (textual) \\
Simulation & No & Yes \\
Optimisation of sequencing & No & Yes \\
of process operations & & \\
Optimisation of cutting conditions & Yes & Yes \\
Used programming languages & Foxbase, Visual Fox & Delphi, VB, C++ \\
\hline
\end{tabular}

\section{PARAMETRIC ASPECT AND ASSOCIATION - A NEW METHOD IN CAPP BASED ON GROUP TECHNOLOGY}

Utilising Group Technology principle in CAPP system is very popular and effective method to create the process plan. Planner executes the process plan in the two steps - firstly he must select representative part for a new part. Secondly the planner must modify the retrieved process plan. Modification of process plan is realised according the difference of properties of new part and representative part.

There is a great human intervention. The planner often analyses the retrieved process plan and inserts, deletes or modifies the process operations. A record of machine tools, cutting tools and other machine equipment is manually realised from databases of machine equipment. There is not intelligent support for planner to determine that process operations have to be deleted, inserted or modified. This decision takes planner according to his experience and knowledge. Therefore the CAPP methodology based on Group technology has subjective character and the software systems operate with big human interventions.

Authors, according to the above-mentioned remarks and disadvantage of Group Technology principle, make a proposal of new approach. This approach consists of parameterisation of process plan and association with part features. The association is realised in two levels and it is made between the following features:

- part feature and process operations (Fig. 3),

- part feature and machine equipment (Fig. 5).

\subsection{Part feature and process operations}

Association between part features and process operations creates the link between design features and manufacturing features located in process plan. Part representative will be described 
according the design features (feature modelling). We take a process operation as manufacturing feature. It is necessary to create link between the design features and manufacturing features.

Fig. 3. Association - link between design features and process operations

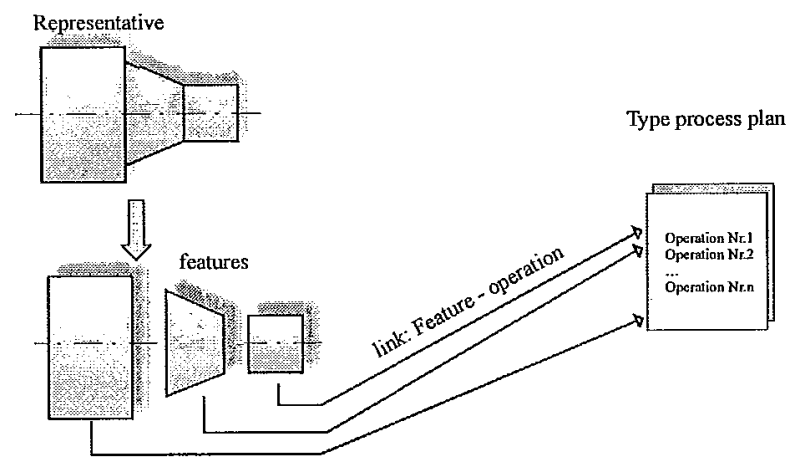

A new part is also described according to feature modelling. In case of process planning for new part, computer system compares the design features between new and representative part. Following, there is the selection of manufacturing features from representative process plan corresponding to design features of new part. Process planning will be more objective and CAPP system will have a higher level of intelligence.

Fig. 4. Comparing of design features of new and representative part

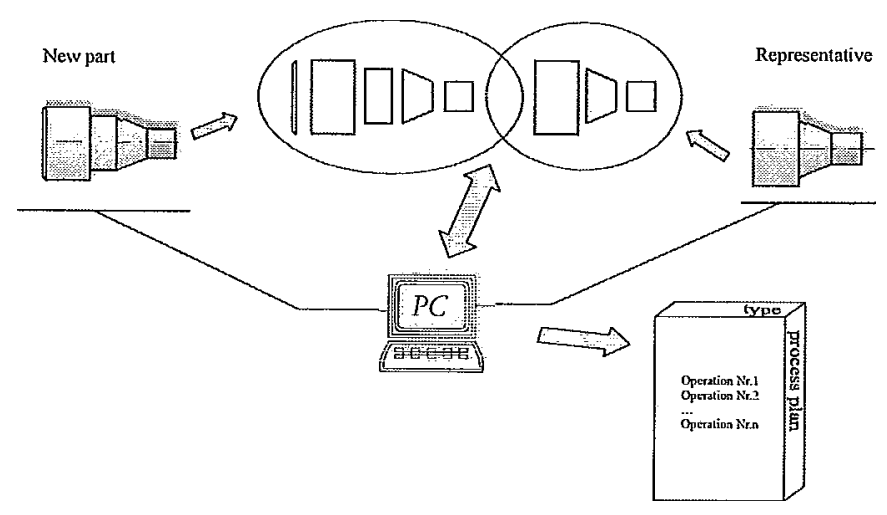

\subsection{Part feature and machine equipment}

Association between part features and machine equipment is another very important task forintelligent CAPP system. The association helps to insert and modify the process operations. Each real design features is machine-made by concrete machine tool, cutting tool and at concrete work clamping. Creating knowledge base based on production rules consist of the real design features and the concrete machine, cutting tools and work clamping of real workshop. If the planner inserts a new operation, he selects for concrete design feature of corresponding machine equipment. It is another contribution to increase intelligence of CAPP system. 


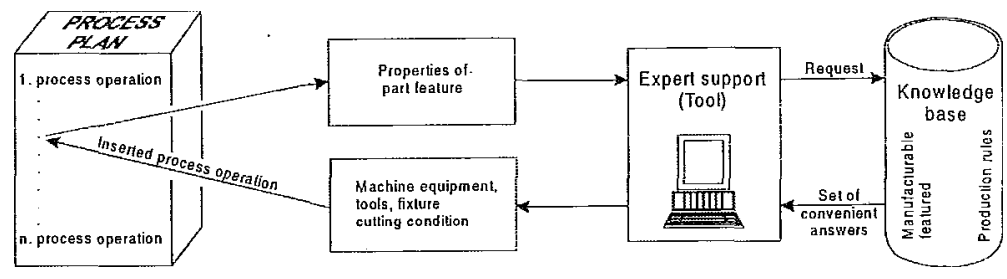

Fig. 5. Principle of insertion of process operations

The disadvantages of current CAPP system based on Group Technology concern the quantity of interventions during modifying of process plan. Planner inserts and modifies the process operation according to his theoretical knowledge and experience. There is not expert support to help modifying the process plan. The new approach consists of parameterisations and association solves the above-mentioned disadvantage of Group Technology. Association in CAPP system gives a higher intelligence to CAPP system. Process planning is more objective.

\section{SEVERAL IMPORTANT ASPECTS OF METHODOLOGY FOR GENERATIVE CAPP SYSTEM}

The generative approach of CAPP is the exact principle of automated proposal of the process plan. The process plan for a new part is automatically synthesised. The generative CAPP systems create the process plan from the knowledge manufacturing databases according to a CAPP methodology. The generative approach is based on generating a plan for each component without referring to the existing plan. The basis for the applied principle is the mathematical description and modelling of:

- part,

- manufacturing equipment,

- manufacturing knowledge,

- process operations,

- process planning.

\subsection{Modelling of the process operation, plan and planning}

A representation and modelling of the process operation, process plan and process planning is the basis for process planning methodology. It is seasonable to distinguish representation and modelling of:

- process operation,

- process plan,

- process planning,

The process or manufacturing operation model is the internal representation of manufacturing equipment (machine, cutting tools, fixture) and other significant parameters (cutting condition) used for manufacturing of one feature. The process plan model is internal representation of all 
manufacturing equipment and corresponding significant parameters used for manufacturing all features, i.e. the whole part. The process planning model is a determination of all states occurring between the raw stock and final part. State count is a finite number. Each state is realised with process operation. The computer based model technique for the process planning requires different types of abstraction level and suitability for analytical formulation.

\subsection{Semiproduct}

The transformation of a raw stock into a product is realised through a semiproduct. The semiproduct may include the surfaces and features that are not in the final part. The semiproduct properties are modified after each machining operation. Individual semiproducts differ from the finished and rough allowance. It is important to determine various semiproducts occurring between the raw stock and final part. The semiproduct determination can be realised from the raw stock to the final part or from the final part to the raw stock. Consequently, there are the following planning methods:

- forwardplanning and

- backward planning.

According to forward planning method, the finishing and rough allowances are taken away from raw stock. Whereas, according to backward planning method, the finishing and rough allowances are added to the final part. Each geometrical change of part in machining process is originated by removing of material volume with concrete machine equipment from individual semiproduct. The machine equipment is entitled as transformer or technological process operator. Each removing ofmaterial volume is the basic manufacturing feature done with some combination of the machine tool, cutting tool and fixturing. According to this consideration it is possible to state that the model of the process plan is such as follows:

- removing material volume,

- semiproduct,

- transformer.

\subsection{Technological model of the part}

The process planning in a manufacturing may generally be defined as development of set of instructions describing all the operations required to convert a design into a product. The semiproducts are given by creation of a new surface or features in machining process. The semiproduct contains no features included in the final part model. Each semiproduct has a new property at least. The new property can be geometrical (form, dimension) and physical (e.g. hardness). Subsequently, the process plan determines how to manufacture all semiproducts. The transformation of raw stock to the final part through the semiproducts is realised with concrete machines, cutting tools and fixtures. All the manufactured surfaces are situated in the technological model of part. The model contains the surfaces as follows:

- raw stock,

- semiproducts,

- final part (Fig. 6.). 
The first problem is to determine the geometry of all surfaces situated in the technological part model. Each geometrical product change in machining is originated by removing the material volume from semiproduct by the concrete machine equipment. Moreover, it is important to determine qualitative properties of semiproducts. However, it is appropriate to model the process plan with the backward planning methods. The individual semiproducts are modelled adding the finished and rough allowance to the final part. These planning methods are easier and there is less time spent to determine the all semiproducts.

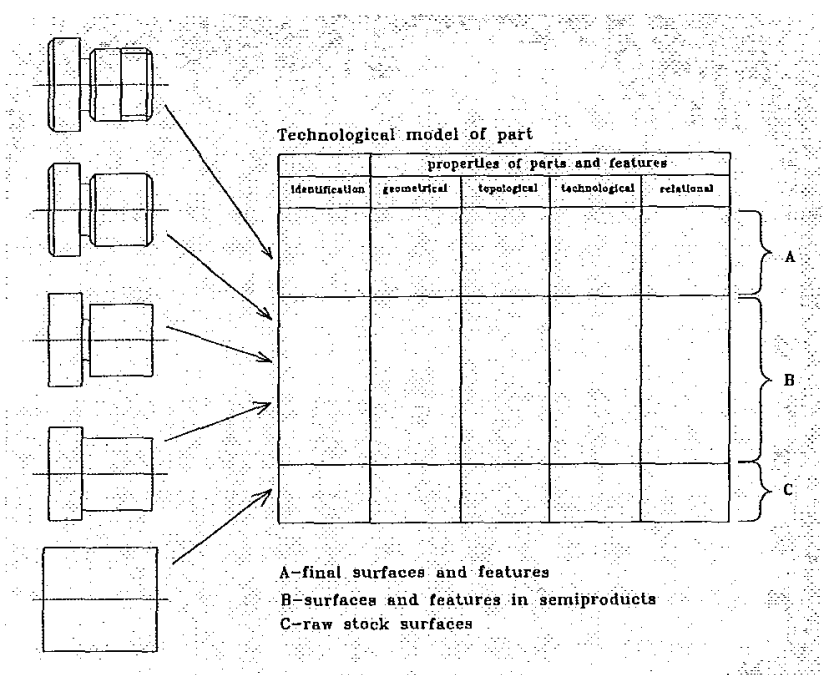

Fig. 6. Technological model of part

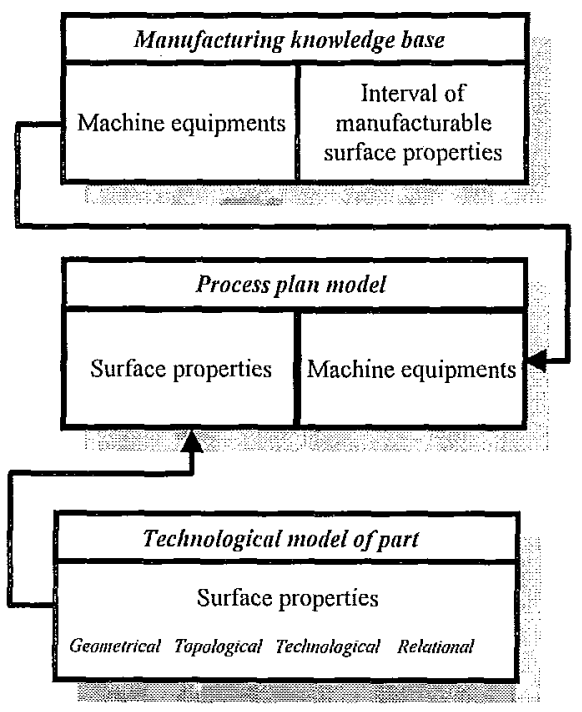

Fig. 7. Principle of creation of the process plan model 
After determining the semiproducts, the next problem consists of determination the machine equipment for each semiproduct of technological model part.

The external representation of the process plan (textual process plan, pictographic process plan, NC code and simulation code) came into existence from the internal process plan. For all four mentioned external representations only one internal representation exists. The internal form of the process plan is transformed to one of existing external process plans by a generator program. The internal process plan representation of the generative CAPP system originates from (Fig. 7.):

- technological part model,

- model of manufacturing knowledge.

\section{CONCEPTION OF DESIGN CAD/CAPP SYSTEM}

The basic aspects of designed CAD/CAPP system characterised are as follows:

- basic characteristic of CAD/CAPP system: Fig. 8,

- CAD system: Autocad R14, Cadkey97, SolidEdge,

- outputfrom CAD system:

- neutral files: IGES, STEP 203, STEP 214,

- textual files with defined data structure,

- $C A D$ data: feature based modelling,

- input to CAPP system: production model of part (geometrical and un-geometrical data). There will be used various inputs to CAPP system - from neutral files such as DXF, IGES, STEP 203 to complete description of part (STEP 214),

- basic principle of process plan modelling: - mathematical modelling based on manufacturing features,

- basisfor CAPP system: kernel based on Group Technology methodology and generative methods of process planning,

- knowledge of process planning: Manufacturing knowledge should consist of the following knowledge (represented as production rules):

$\Rightarrow$ process knowledge,

$\Rightarrow$ fixturing knowledge,

$\Rightarrow$ heat treatment knowledge,

$\Rightarrow$ knowledge of product feature structure.

- modelling of process plan: according to principle of removed volume of material. The internal representation of process plan in CAPP system: technological model of part. The model contains the surfaces as follows:

$\Rightarrow$ raw stock,

$\Rightarrow$ semiproducts,

$\Rightarrow$ final part.

- SW used in CAPP system: FoxPro (databases, knowledge), Exsys (management of knowledge), Delphi (kernel of CAPP, control and management the process planning),

- output from CAPP system: textual, pictographic process plan, and NC code. 


\subsection{Challenge for collaboration}

Building the integrated CAD/CAPP system is a time demanding task. The task requires the theoretical elaborating, working out the serious methodology of process plan and using the ad-

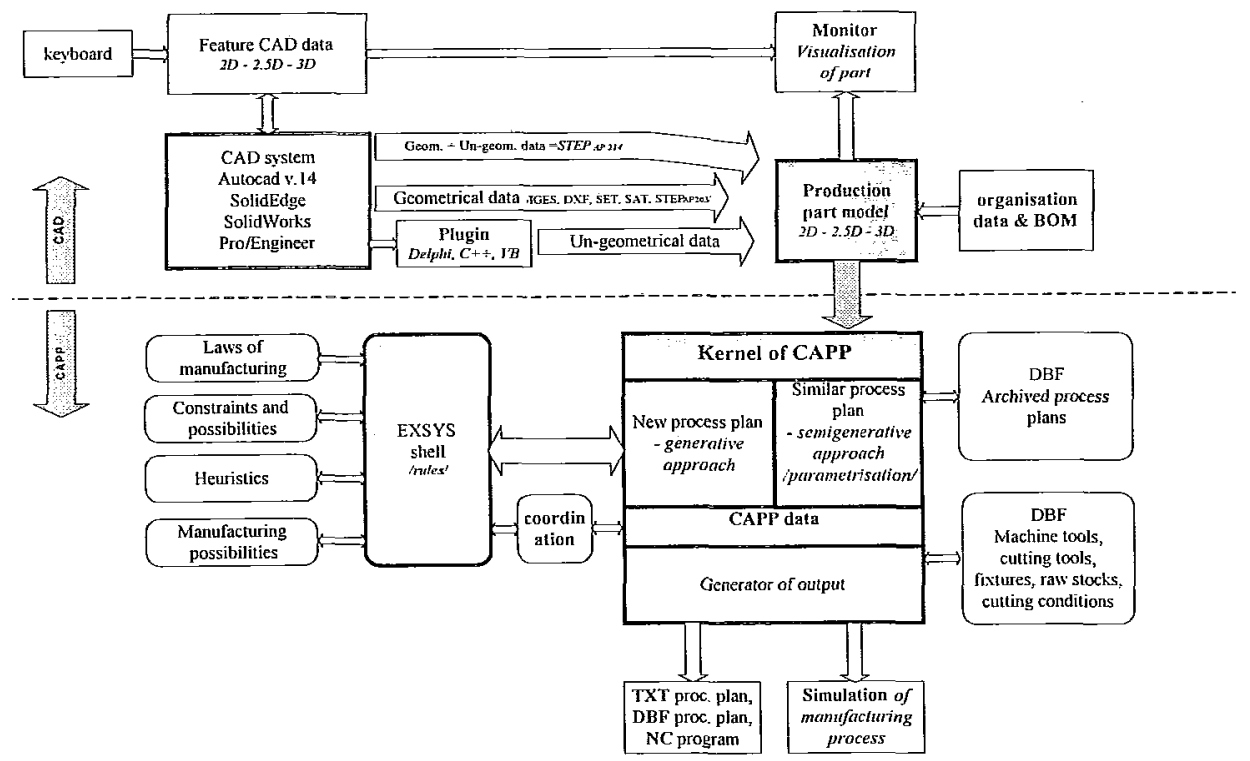

Fig. 8. The basic conception of CAD/CAPP system

vanced programming technique. Therefore, several people should execute the system. The system will be opened and there is a possibility to engage the research team from the other university units.

\section{References}

[1] Bedworth D. D., Henderson M. R., Wolfe P. M., Computer integrated design and manufacturing, McGraw-Hill, New York, 1991.

[2] Crama Y., Oerlemans A., Spieksma F., Production planning in automated manufacturing, Springer Verlag, Berlin, 1994.

[3] Chang T. C., Expert process planningfor manufacturing, Addison-Wesley Publ., Massachusetts, USA, 1990.

[4] Samek A., Duda J., Manufacturing knowledge as a methodolical base in the planning ofmachining process, Proc. CIM, Zakopane, 14-17. 5. 1996, vol. III, 441-448.

[5] Janáč A., Osanna P. H., Kurie I., Contribution to modelling of process planning. In: Journal Automation und Messtechnik, 4/1997, Springer Verlag KG, Vienna, 182-185.

[6] Mičieta B., Mičietová A., Verbindung CAP - PPS - CIM. In: Proceedings of CA Systems and Technologies, Int. DAAAM Workshop, 19. 3. 1997, Žilina, 95-98.

[7] Velišek K., Design methodology ofschediding strategies and scenarios of complex flexible systems. In: Vedecké práce MtFSTU. Zv.5, 1997, 71-80.

[8] Marcinčin J. N., CAPE (Computer aided production engineering) technológie a ich zaradenie do štruktúry CIM. In: Zbornik ATPVZvolen, TU Zvolen, 17. 9. 1998, Zvolen, 59-63. 